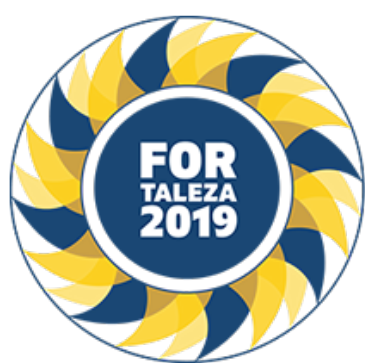

\title{
PREVALENCE CARDIOVASCULAR RISK FACTORS AND SYMPTOMS IN SPONDYLOARTHRITIS PATIENTS AND IT'S CORRELATION WITH ELECTROCARDIOGRAPHIC CHANGES: A TRANSVERSAL STUDY FROM TERTIARY SERVICE END MANAUS - AM.
}

Raissa Pires Medeiros (UFAM, Manaus, AM, Brasil), Matheus Diniz Araújo Teixeira (UFAM, Manaus, AM, Brasil), Maykom Lira Barbosa (UFAM, Manaus, AM, Brasil), Júlia Cristina Souza Alves (UFAM, Manaus, AM, Brasil), Isabelle Louise Cruz Lopo Figueiredo (UFAM, Manaus, AM, Brasil), Gabriel Pacífico

Seabra Nunes (Universidade Nilton Lins, Manaus, AM, Brasil), Marlúcia Nascimento Nobre (UFAM, Manaus, AM, Brasil), Sandra Lúcia Euzébio Ribeiro (UFAM, Manaus, AM, Brasil)

\section{BACKGROUND}

Spondyloarthritis (SpA) is a group of chronic rheumatic diseases with several extra-articular manifestations. Among those diseases are mainly ankylosing spondylitis (AS) and psoriatic arthritis (PsA). The clinical feature is diverse and there are cardiac manifestations that affect around $10 \%$ of the patients. Aortitis, conduction disorders and atrioventricular conduction block are prominent in this context. Evaluate the prevalence of risk factors and symptoms for cardiovascular diseases and it's correlations to electrocardiographic changes in patients with AS and PsA.

\section{MATERIALS AND METHODS}

It's a transversal study with AS and PsA patients from a Tertiary Service from Manaus - AM. The patients consent to participate of the study. The patients were asked to fill a form about the main cardiovascular risk factors and symptoms. After, all of them gone throw electrocardiographic evaluation which was analyzed by a cardiologist, and compared to the clinical features to indentify correlation between the risk factors and symptoms and electrocardiographic(ECG) changes.

\section{RESULTS}

Our sample consisted of 60 patients, in which 16 were PsA and 44 had AS. The age of the patients ranged from 26 to 86 years old, with the median age of 50 years old. The male/female ratio was 3,6:1. From our sample, 26 patients had at least one risk factor or symptoms of cardiovascular disease; 12 of them had associations of risk factors and symptoms and 14 had only one isolated risk factor. After (ECG) examination, we identified 5 altered ECG. All of the ECG changes were associated with a clinical feature, being: One with precordial pain had a delay in the conduction AVL; one with diabetes and arterial hypertension $(\mathrm{AH})$ had an early repolarization and slow progression in V5 and V6; other with hypertension had right bundle branch block; other with hypertension had delay in the conduction to right branch; one with thoracic pain, dyspnea and dyslipidemia had a delay in the conduction; and the last patient had hypertension and a postero-anterior divisional block.

\section{CONCLUSION}

As we could see, there was a good correlation between risk factors and symptoms to electrocardiographic changes in our patients. The overall prevalence of alteration was of $10 \%$. In conclusion, our patients had a large variety of ECG changes, meaning that we need to pay a close look to those patients and the cardiovascular complains, in order to early diagnose a possible life threatening disease. 